
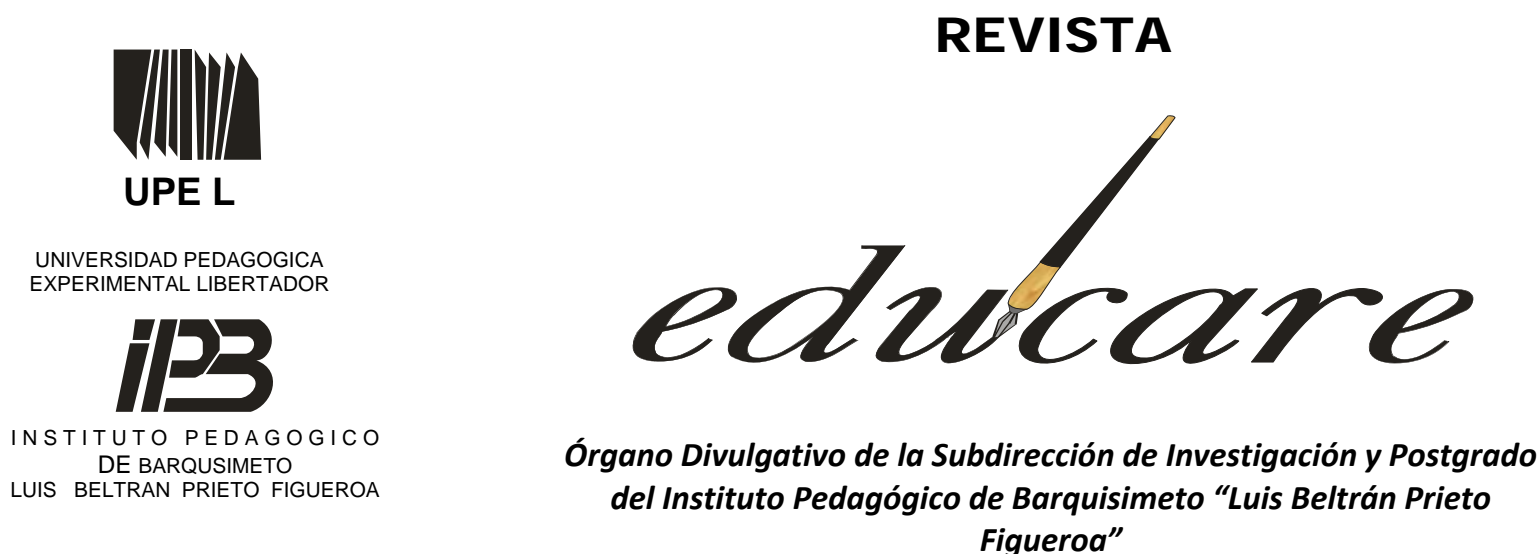

Figueroa"

BARQUISIMETO - EDO. LARA - VENEZUELA

NUEVA ETAPA

VERSION ELECTRÒNICA

DEPOSITO LEGAL: ppi201002LA3674

ISSN: 2244-7296

Volumen $14 \mathrm{~N}^{\circ} 2$

Mayo-Agosto 2010

\title{
LA RED DE INTERNET COMO MEDIACIÓN PARA EL APRENDIZAJE DE LA FILOSOFÍA
}

\section{INTERNET AS A MEANS TO LEARN PHYLOSOPHY}

\author{
Esequiel L. Rojas T. \\ Universidad Pedagógica Experimental Libertador \\ Instituto Pedagógico de Barquisimeto \\ “Luis Beltrán Prieto Figueroa"
}




\section{LA RED DE INTERNET COMO MEDIACIÓN PARA EL APRENDIZAJE DE LA FILOSOFÍA.}

\section{INTERNET AS A MEANS TO LEARN PHILOSOPHY.}

\section{ENSAYO}

Recibido:12-03-2010

\section{RESUMEN}

El presente artículo refiere una revisión documental que pretende reflexionar sobre la posibilidad de que la red de Internet, a través del hipertexto, los grupos de discusión y el correo electrónico, funcionen como un espacio mediador para el proceso de enseñanza aprendizaje de la Filosofía. Para esto se revisa el pensamiento filosófico de Martin Heidegger según el cual la tecnología es ontológicamente una mediación entre el hombre y el ser del mundo. Posteriormente se analizan los aspectos teóricos que subyacen a las tecnologías mencionadas en su capacidad para favorecer el aprendizaje de la Filosofía. Se concluye que, efectivamente este instrumento tecnológico induce al hombre a la comprensión del mundo, de sí mismo y de su lugar dentro del mundo, por lo que está contribuyendo en la realización existencial propia del hombre. Si la tecnología facilita esta reflexión, entonces estará cumpliendo su papel de mediadora entre nosotros y la esencia de nuestro quehacer técnico y será un puente que renueve el lazo entre el hombre y el Ser.

Descriptores: Enseñanza de la Filosofía, Tecnología Educativa, Filosofía de la Tecnología.

\author{
Esequiel L. Rojas T. ${ }^{*}$ \\ UPEL-IPB
}

Aceptado: 28-07-10

\begin{abstract}
This paper offers some considerations on using Internet -hypertext, chats, and e-mails- as a means to teach philosophy. This study is supported, on one hand, on Heidegger's philosophical ideas on technology and its relationship with human beings; on the other, on applied theories of technology. The study shows that Internet has a positive impact on the teaching of philosophy since it facilitates man's comprehension of the word, of himself, and his role as a world citizen; therefore, it contributes to man's existential realization. It is concluded that Internet does fulfil its role as mediator among men and the essence of their technical task, becoming a bridge for the renewal of man and being.
\end{abstract}

Keywords: Teaching philosophy, educational technology, philosophy of technology 


\section{INTRODUCCIÓN}

Sobre la sociedad tecnológica en la que desde hace algún tiempo vivimos, existe una vasta literatura que ha intentado describirla, comprenderla y darnos atisbos sobre la forma correcta de habérnoslas con ella. Mucho de lo que hace pocos años nos parecía utópico, se ha convertido ya en obsoleto. La mayoría de las amenazas de los profetas del desastre y de las promesas de los visionarios del futuro sobre el avance de la tecnología, las tenemos entre nosotros.

Un aspecto resaltante de este avance de la tecnología en nuestra sociedad es su uso en el campo educativo. Las ventajas que nos ofrecen las Tecnologías de Información y Comunicación para la enseñanza aprendizaje son, por su naturaleza, infinitas. $\mathrm{Y}$ aunque igualmente es abundante la literatura que sobre esto puede conseguirse, la misma ilimitación de las tecnologías hace superflua cualquier pretensión de afirmar que se han agotado sus matices.

La irrupción de nuevos fenómenos en tecnologías "tradicionales" confirma esta aseveración: por ejemplo, las recientemente aparecidas redes sociales como el Twitter, soportadas por vía Web y por vía celular, ofrecen nuevos espacios de reflexión sobre la ilimitación posible de la educación tanto en el tiempo como en el espacio. Asimismo, podemos mencionar los sitios informales como el Facebook y los Bloks o Weblogs, que están siendo aprovechados por los docentes para complementar o mediar su interacción con los estudiantes. No hablemos, por supuesto, del impacto social o político que actualmente están teniendo tales redes.

A la par de todo esto, a principios del siglo XX en la Filosofía surgió una nueva rama o tendencia que se ocupa precisamente de la tecnología y la ciencia que la respalda: la Filosofía de la Tecnología. Y aunque sólo tardíamente vino a denominársele de esa forma, la mayoría de los pensadores del siglo XX dedicaron algunas de sus más importantes reflexiones. Entre los que destacan podemos nombrar a Heidegger, Ortega, García Bacca, Marcuse, Habermas, Mitcham, Ellul, Hottois, Ladriére y otros muchos, algunos de los cuales han vivido las consecuencias más duras de la era tecnológica. 
Y si el fenómeno de la tecnología ha sido objeto de estudio por parte de la Filosofía, lo ha hecho desde distintas perspectivas, a saber: desde la Antropología: que estudia la técnica como producción y prolongación humana; desde la Epistemología: que describe sus capacidades de potenciación del conocimiento; desde la Ética: en cuanto reflexiona sobre el impacto moral que tiene sobre los seres humanos y su hábitat; y desde la Ontología: por la que se estudia la esencia radical de la técnica.

En lo que respecta a este artículo, se suscribe a las cuatro perspectivas de análisis, por cuanto considera la raíz antropológica de la técnica, busca su esencia radical, y reflexiona sobre sus potencialidades educativas, y finalmente, sus consecuencias éticas.

Es así que el mismo dirige su atención al fenómeno de la técnica moderna o tecnología (consideradas en este escrito como sinónimas). Tiene como propósito resaltar, desde la Filosofía, el carácter de mediación de la misma entre el hombre y el ser del mundo. A su vez, ese carácter de mediación puede verse reflejado en las potencialidades mediadoras que puede ofrecer la tecnología en el aprendizaje de la Filosofía, aspecto sobre el que suele hallarse poca literatura. Por ello mismo, se propone además estudiar cómo la red de Internet, a través del hipertexto, los grupos de discusión y el correo electrónico ofrecen características que permiten formar competencias básicas para el aprendizaje de la Filosofía.

\section{LA TÉCNICA COMO MEDIACIÓN}

Lo propio del filosofar, y en general del afán cognoscitivo del ser humano, es la búsqueda de respuestas últimas a todas sus interrogantes. Esto es, comprensión de los fenómenos y la aprehensión de las esencias de las cosas. En el intento de comprensión de la naturaleza del fenómeno tecnológico, frente a su universalidad, la totalización que obra en el mundo humano, conviene preguntarse por la esencia de esta realidad que hoy nos cubre y nos envuelve. Además, vale decir que el ámbito de la tecnología no puede reducirse sólo a los aparatos, los métodos y las técnicas sino que se extiende a todos los entes en general, incluyendo especialmente al hombre, quien es su creador y a la vez el principal sujeto y objeto de su desenvolvimiento. 
Se impone, entonces, traer uno de los principales significados que Martín Heidegger (1994, pp. 15-22) otorga a la técnica: ésta constituye un desocultar o desvelar el Ser al hombre. En Heidegger, lo que sea el Ser no sólo es complejo, sino además inacabado: el pensador alemán se resistió siempre a ofrecer definiciones o concreciones del Ser. A pesar de eso, a partir de sus escritos y de la tradición filosófica, el Ser puede entenderse como la comprensión última del mundo, el sentido originario y final de todo lo que hay, inclusive, el sentido mismo de la vida humana. Y entre los entes del mundo, el único a quien el Ser puede revelarse, el único capaz de preguntarse por el Ser, es el hombre, a quien Heidegger llama el Dasein: el Ser-ahí (1998, p. 30).

Sin embargo, la técnica no es sólo un modo de desocultar el Ser, sino que además, con frecuencia le oculta el Ser al hombre: la técnica es también el colmo del olvido del Ser que ha padecido el hombre a través de la historia. La pretensión de occidente de conocer, explorar, explotar y sacar provecho de todo, le ha nublado la visión del Ser: cuando el ser humano busca interesada y pragmáticamente el mundo, entonces deja de percibir el verdadero sentido del mismo. La técnica es, por tanto, el último intento del hombre por apoderarse de todo lo que hay a su alrededor, incluso de sus semejantes.

Para desmenuzar esto, partamos de la convicción de que el hombre se encuentra situado en una realidad o mundo en el que ha de hacer su vida y desarrollar su existencia. Y que esta relación con su entorno no le es accidental, sino que forma parte de su misma constitución esencial o existencial. Pero a diferencia de otros seres vivos, el hombre no sólo ha de adaptarse al medio que le circunda, sino que incluso ha de adaptar el ambiente para hacerlo suyo, de forma que le permita realizar su ser según su naturaleza humana.

A esta actividad fundamental Queraltó (1993, p. 20) la llama "asentamiento de la realidad”, e implica que el hombre construya las bases que sustentan su manera de ser en el entorno. Esto significa que el ser humano no sólo está en el mundo, además quiere situarse para permanecer, con proyección para el futuro, para el quehacer total y continuo de sí y de su vida.

Y para llevar a cabo esta actividad fundamental, el hombre se sirve de otro quehacer suyo, también primigenio, que deriva de su estructura existencial básica: el 
conocimiento. Sólo conociendo al mundo podrá asentarse en él. Frente al mundo real que le interpela, la respuesta del hombre es la del conocer; y ese conocer es también una mediación entre el hombre y el mundo real, que por un lado le distancia del mundo para que pueda aprehenderlo, y por otro, le acerca el mundo a su intelecto. Además, el conocimiento invita al hombre a adentrarse en sí mismo y autocomprenderse como ser humano, en sus estructuras más profundas y en las que le vinculan con el medio y con lo que es trascendente al entorno físico.

Pero para Queraltó (ob.cit, pp. 21-25) ese conocimiento no responde a una intención teorética sino más bien a una condición existencialmente pragmática: su objetivo es conseguir al hombre su asentamiento en la realidad, exige la puesta en práctica de sus resultados.

Esta puesta en práctica de tales logros la lleva a cabo el hombre mediante la actividad técnica, cuya finalidad originaria es la realización de los fines cognoscitivos humanos, dirigidos en primer término y de forma inmediata a producir el asentamiento efectivo del hombre en la realidad. No se trata simplemente de una mera satisfacción de necesidades, sino que señala a un plano más profundo: emplazarse consistentemente en el mundo, hacer efectivo tal asentamiento. De ahí que la técnica o tecnología no está ligada a una época única de la historia sino que se enraíza en el ser mismo del hombre. En este sentido, la producción tecnológica contiene a algunos caracteres esenciales:

Adaptada a un fin determinado: el hecho u objeto técnico está diseñado con miras a desarrollar o completar una determinada función humana, su razón de ser depende inicialmente del hombre, adquiere un valor de servicio para el hombre.

Definida por relaciones externas: es esencialmente "relativa a", es decir referencial a la consecución de su función propia, la cual le viene impuesta de fuera, por el hombre. Tiene una dimensión instrumental: Es un medio para conseguir determinados fines, que en principio, se supone rinden un servicio al ser humano, de allí le brota su verdadero y esencial valor. Ahora bien, cuando se pierde esta orientación originaria de mediación entre el hombre y el mundo, la tecnología adquiere autonomía por sí misma y entonces se busca la eficacia por la eficacia, el progreso por el progreso; lo cual supone 
una reducción en la concepción del valor del ser humano, quien pasa a ser, entonces, un medio más para el progreso tecnológico mismo.

Igualmente, posee un criterio de utilidad: hace referencia al cumplimiento de la función técnica, pero no sólo por el valor de la simple eficacia que ella entrañaría, sino porque esa función se encamina a resolver una problemática humana. De nuevo, cuando la referencia a la utilidad pasa a ser el criterio único, la técnica se convierte en instrumento de dominio, entonces se desvincula por completo de su raíz originaria y se convierte en fin en sí misma.

De este modo, como actividad cognoscitiva y como actividad transformadora de lo real, la técnica supone una determinada forma de acceso epistemológico al mundo. Y su valor está definido por cuanto descubre un tipo específico de orden en la realidad, siendo, por tanto, una manera de develar los entes. Es decir, se ve en la necesidad de seleccionar los caracteres de lo real que son susceptibles de ser conocidos según los criterios que contribuyan al éxito del asentamiento del hombre.

Y la transformación tecnológica de la realidad involucra nuevas posibilidades de comprensión y accesibilidad al mundo, así como el diseño de nuevos modelos instrumentales; por ello, también, todo logro cognoscitivo de la actividad tecnológica influye en la visión de la realidad del ser humano, pues supone una modificación permanente de la actividad racional y de su manera de conocer y entender.

Ahora bien, Ladrière (1973, pp. 80-85) ve en este "asentamiento de la realidad" del hombre la posibilidad de llegar a una vida feliz, pues es la realización de una tarea que el Logos o Voluntad originaria ha encomendado al hombre para que la realice. Dicha tarea remite a la felicidad, puesto que el resultado específico de la misma es el bienestar del hombre: su enraizamiento en el mundo como su hábitat propio según su naturaleza, su lugar ontológico.

No obstante, esa vida feliz y bienestar no debe referirse únicamente a la dimensión físico-material sino a todo el conjunto de la ubicación existencial del hombre; por ello para Ladrière la felicidad sólo será plena en la medida en que la técnica medie la adecuación de la existencia ético-metafísica del hombre con la Voluntad Originaria. Esa existencia ético metafísica es la que se corresponde con la 
dignidad que le es propia, la dignidad de persona humana: con una realización corporal a través del gozo de los bienes materiales, una realización intelectual por medio de la educación, realización de alteridad mediante el amor, y una realización espiritual mediante la experiencia personal con lo trascendente.

De esta manera, puede señalarse que para que el hombre logre alcanzar su bienestar concebido integralmente, es preciso el quehacer tecnológico como condición necesaria, más no suficiente. Esto es, la técnica concebida como medio por el que el hombre sea capaz de: comprender la misión que le compete en el mundo, conocer la naturaleza del mundo sobre el que ha de asentarse, y transformar su entorno para facilitar su realización existencial en todas sus dimensiones.

Si el avance tecnológico pierde de vista esta raíz originaria que le otorga sentido, entonces se cambian los roles, ella pasa a fin y el hombre pasa a ser medio. De esa forma no será el hombre el que deba desplegarse para su realización existencial, sino que será la tecnología la que se despliegue con dinamismo propio en el que el hombre sea un instrumento más de su dominio.

A la luz de esta visión, si contemplamos y disponemos la producción tecnológica como una contribución a la plenitud de la existencia humana, entonces, el despliegue tecnológico puede ser considerado como una auténtica personalización. En especial si, según la postura Heideggeriana, la tecnología actúa como un desvelar del Ser; y pues el ser que primeramente conocemos es nuestra propia existencia, la tecnología tiene también un papel protagónico en nuestro autoconocimiento.

Es por ello que gracias a los avances tecnológicos el hombre va disponiendo de nuevos elementos para su propio estudio y comprensión. A la par de ello ha ido entendiendo su lugar dentro del Cosmos, integrando un dinamismo que a la vez que le supera infinitamente, se le manifiesta como en servicio de su realización plena.

Desde esta perspectiva mediática es que puede llegar a plantearse una personalización de la tecnología, es decir, un quehacer tecnológico que propicie la realización de la persona humana en todas sus dimensiones. Por esta vía, la tecnología, aunque no otorgue por sí misma la felicidad humana, concebida como realización existencial, estaría contribuyendo eficazmente en su consecución. Y, además de las 
experiencias dramáticamente dolorosas del uso de la tecnología, hoy también contamos con abundantes confirmaciones de que puede usarse en la búsqueda del bien de la humanidad.

Y aunque es verdad que el precio que estamos obligados a pagar por estos avances es por un lado, su complejidad en lo que respecta a las muy diversas secuelas materiales y de sentido que acarrean, y por otro, su fragilidad pues no siempre somos capaces de prever sus consecuencias, nuestra labor es intentar asegurar que la gestión de estas tecnologías prime siempre el papel central y final de la persona.

Por todo lo dicho, para Heidegger, pese a que en la técnica moderna se encuentra el más grande olvido del Ser, reside también en ella lo salvador, es decir, el desvelamiento del Ser: la situación insostenible del avance desenfrenado de la técnica ocasionará que el hombre reflexione, busque formas más benevolentes y respetuosas de relacionarse con el mundo, y que inclusive busque la manera de comprender mejor la misma esencia de la técnica:

Yo veo la situación del hombre en el mundo de la técnica planetaria no como un destino inextricable e inevitable, sino que, precisamente, veo la tarea del pensar en cooperar, dentro de sus límites, a que el hombre logre una relación satisfactoria con la esencia de la técnica. (Heidegger, 1976, p. 78).

Una relación satisfactoria con la técnica, de captación de su verdadera esencia, trae consigo la comprensión de su papel mediador en nuestra relación equilibrada con el mundo y entre nosotros mismos. Ese carácter mediador sería, insistimos, la personalización de la técnica.

Un intento de esta personalización de la tecnología puede ser el uso de la Internet para la educación. En ella destaca el papel mediático de las tecnologías mientras el enfoque finalista se centra en la formación de las personas humanas. Más específicamente aún se puede establecer el uso instrumental de un sitio web en el que se faciliten actividades y recursos de enseñanza-aprendizaje de la Filosofía, es decir, para la comprensión del Ser. 
De ahí que haya nacido este escrito: la tecnología puede ser usada como medio para la comprensión de las inquietudes más profundas del hombre, y esto puede llevarse a cabo a través de una página de Internet enseñanza y aprendizaje de la Filosofía. En cada una de sus secciones se han de propiciar espacios en los que sus usuarios tengan la oportunidad de reflexionar sobre sí mismos, sus presupuestos cognoscitivos, sus principios de acción más profundos, sobre las consecuencias de sus acciones, sobre el ser radical de las cosas.

Los espacios pueden servir para pensar el mundo, el mundo de lo natural, es decir el Cosmos: su origen, su evolución, su destino, su sentido; para pensar en las riquezas y la fragilidad de la naturaleza que se nos ha encomendado. Pero también el mundo humano: el mundo de las relaciones sociales, el mundo de la educación y sus principios, el mundo de lo artificial, el mundo del devenir tecnológico, todas, actividades fundamentalmente humanas. Y aún más para pensar en el mundo Trascendente, el mundo de lo sagrado.

En tales espacios se propiciarían las actividades que fomenten la reflexión: la lectura sobre temas y problemas filosóficos puede estimular esta capacidad específicamente humana. También se ha de impulsar la comunicación: la reflexión se vigoriza superlativamente cuando se comparten las inquietudes propias con otras personas. Además se debe favorecer la discusión: el encuentro entre pensamientos coincidentes o discordantes conviene para la potenciación de habilidades de pensamiento crítico y de elaboración de argumentos fundados, lo cual es fundamental para asumir posición ante los fenómenos que se suscitan a nuestro alrededor. Finalmente, se puede dar oportunidades para la producción filosófica de todos sus actores mediante los espacios a construir de manera colaborativa o individual, permitiendo el enriquecimiento del debate sobre la búsqueda de sentido que ha caracterizado la historia humana.

De esta manera, una página de Internet se puede disponer como mediadora entre sus usuarios y lo real; entre estudiantes y docentes; entre estos actores y los problemas fundamentales que estudia la filosofía. Y según lo comentado en los párrafos precedentes, en la medida en que este instrumento tecnológico induce al hombre a la 
comprensión del mundo, de sí mismo y de su lugar dentro del mundo, entonces está contribuyendo en la realización existencial propia del hombre.

Por tal razón, vale la pena plantearse la pertinencia de aprovechar las ventajas de una página web de apoyo a los cursos de Filosofía, desde la visión de la tecnología educativa, es decir desde sus presupuestos pedagógicos. Eso es lo que se hará en los siguientes apartados.

\section{DESCRIPCIÓN DE LA RED DE INTERNET}

La red de Internet o "red de redes”, cuya popularización ha venido en aumento vertiginoso en los últimos años, "es un conjunto de computadoras unidas entre ellas a través de líneas telefónicas, cable coaxial, fibra óptica, satélite, etc., que pueden intercambiar información en diversos formatos, texto, gráficos audio y vídeo" (Escamilla, 1998, p. 124). Hoy en día existen numerosos trabajos dedicados a subrayar las potencialidades de enseñanza-aprendizaje de Internet, presentados desde muchas lenguas y desde muy variadas situaciones educativas.

Algunas de las características que resultan atractivas de la Internet desde el punto de vista educativo son:

a) Capacidad hipermedia, con la infinidad de posibilidades que esto implica.

b) Trascendencia sobre los límites geográficos y de tiempo, lo que facilita la educación a distancia.

c) Disponibilidad de software de clientes, servidores y de herramientas de edición de dominio público para diferentes plataformas.

d) Simplicidad en la sintaxis del lenguaje HTML, lo cual le da una característica de universalidad.

e) Acceso simple y uniforme a los recursos, simplemente navegando a través de los distintos vínculos.

f) Acceso a cantidades ilimitadas de información.

g) Posibilidad de modificar los contenidos en función de la realimentación obtenida. 
h) Interactividad: posibilidad de utilizar formularios de entrada de datos y ejecutar procesos en función de las peticiones de los clientes.

Entre los inconvenientes que se plantean se encuentran:

a) El estudiante no siempre tiene los conocimientos necesarios para resolver los problemas técnicos que surgen inevitablemente de su uso.

b) La mayor cantidad de información relativa a casi todas las disciplinas del conocimiento están escritas en inglés, por lo que se requiere el dominio de este idioma para acceder a una buena parte de recursos.

c) La sensación de sentirse perdidos en el ciberespacio que a menudo experimentan los nuevos usuarios.

d) El procesamiento de formularios y de la publicación de información requeriría llevar a cabo cierta programación por parte de los profesores, por lo que siempre dependen del soporte informático.

Por su parte Welsh (1998, p. 22) opina que los educadores deben estar en Internet, pues ofrece asombrosos recursos de información, en especial desde el WWW, limitados únicamente por los criterios de búsqueda que usemos. Así, se pueden descargar lecciones enteras, libros, artículos de interés, listas de correo y de noticias, grupos de discusión, todo esto con sólo hacer un clic. Asimismo, Welsh (idem) subraya la ventaja de que el lenguaje universal de Internet sea el HTML (Hyper Text Markup Language), pues permite ser creado y decodificado por muchos sistemas operativos, con ello se asegura casi por completo un acceso universal a la red. El hipertexto tiene interesantes aplicaciones desde el punto de vista pedagógico e interactivo, descritas a continuación.

\section{Hipertexto e hipermedia:}

Laurillard (1993, p. 120), comenta que el hipertexto es un software diseñado con la intención de almacenar información relevante de forma que ésta sea accedida sin necesidad de seguir una secuencia, es decir según las necesidades del usuario. Los elementos que lo componen se llaman documentos, los cuales están vinculados entre sí 
mediante un índice o un mapa y se puede navegar entre unos y otros a través de los vínculos creados para tal fin. Esos documentos pueden estar constituidos por texto de variada amplitud, por dibujos, diagramas, gráficos, animaciones, vídeos, sonido, y algunos otros componentes de multimedia.

Aunque Laurillard no discrimina entre hipertexto e hipermedia, en la literatura sobre el tópico se acostumbra a diferenciar el uno del otro: el hipertexto sería un software que sólo incluye documentos de texto vinculados entre sí a los que se accede a través de los vínculos, que generalmente contienen palabras o frases identificadoras del contenido de tales documentos. Haciendo clic en ellas con el ratón del computador se puede ir navegando entre unos y otros documentos. La característica principal, entonces, sería el contenido: los documentos son textuales.

Un documento de hipermedia es un documento de multimedia que no sólo ofrece interacción con textos sino que también contiene vínculos hacia documentos con gráficas, imágenes, vídeos, archivos de sonido, animaciones, presentaciones, acceso a otros documentos de hipertexto o hipermedia. En el hipermedia los vínculos no sólo están constituidos por textos resaltados sino también por imágenes, iconos o gráficos.

Las ventajas que desde el punto de vista pedagógico ofrecen el hipertexto e hipermedia son numerosas: se pueden establecer infinidad de relaciones entre los recursos que puede albergar; el estudiante o usuario decide sobre los recursos que desea explorar o no, por ello, si está bien diseñado ofrece un alto nivel de control por parte del usuario; los contenidos pueden estructurarse de manera que se accedan intuitiva y fácilmente; ofrece un alto grado de independencia al estudiante, por lo que es ideal para la educación de adultos y la educación a distancia.

Adicionalmente, desde el punto de vista filosófico, Vásquez (2004, p. 332) sostiene que frente al texto tradicional, el hipertexto ha revolucionado la forma en la que se nos presenta el conocimiento y accedemos a él. Esto trae consigo nuevas relaciones entre lo real y lo virtual, entre lo natural y lo sintético. A su vez representa una cierta democratización del conocimiento por las múltiples opciones y secuencias de lecturas que nos ofrece, frente a la linealidad, monotonía e imposición del texto impreso tradicional. 
En ese sentido, entre los recursos que se pueden llegar hospedar desde el hipertexto o hipermedia destacan, por su capacidad de proporcionar interacción a los estudiantes, los grupos de discusión y el correo electrónico, dos tecnologías basadas en texto y asincrónicas. Son elementos potenciales de aprendizaje constructivista, según enfatiza Jonassen et al. (1995, p. 16): "El poder de los grupos de discusión y el correo electrónico como herramientas y ambientes de aprendizaje constructivista radica en sus capacidades para facilitar la conversación y la colaboración”. En los siguientes apartados se describirán estas capacidades.

Un ambiente de aprendizaje basado en hipertexto o en hipermedia puede llegar a convertirse en un ambiente de aprendizaje constructivista (Jonassen, et al., 1995, p. 19) en la medida en que posea las características cognitivas necesarias para la construcción del conocimiento. Es decir, que contribuya a mejorar la comprensión de los estudiantes y su transferencia de información, mediante la exposición del mismo material en diferentes momentos y de acuerdo a las distintas necesidades planteadas por cada contexto o propósito educativo.

Asimismo, en cuanto escenario educativo que facilita la educación a distancia, el uso de esta tecnología responde a un aprendizaje constructivista porque considera los conocimientos previos del participante facilitando la edificación progresiva del conocimiento, y porque debe partir del contexto integral del estudiante (Bravo y Montero, 2008, p 55).

El hipertexto o hipermedia, además, promueve las representaciones del conocimiento en los estudiantes de una forma flexible, en especial frente a aquellos campos del conocimiento que por su misma naturaleza no están estructurados y envuelven conceptos complejos, como en Filosofía, por ejemplo. El hipertexto puede ser verdaderamente útil cuando en la lectura de un texto filosófico existen vínculos que nos aclaran lo que significan las categorías más importantes que usa el autor.

Por otro lado, el hecho de que el hipertexto o hipermedia sea una forma no lineal de acceder a la información, según Mason (1998, pp. 49-51) introduce un cambio en la dirección tradicional del aprendizaje: el estudiante puede navegar a través de los distintos vínculos de la página o incluso salir de ella y construir nuevas relaciones entre 
sus contenidos o entre contenidos de varios sitios de Internet. Así "En esta nueva dispensación, el ambiente de aprendizaje es un teatro en el que hay una función continua y en donde tanto estudiantes como profesores son a la vez actores y audiencia, construyendo colaborativamente la historia de la disciplina” (Mason, idem), no sólo el docente tiene el conocimiento, ambos actores lo construyen.

Esta capacidad de apertura del hipertexto hacia la retroalimentación y no linealidad, se adapta perfectamente a la naturaleza de un curso de Filosofía en tanto que docentes y estudiantes deben tener oportunidades para expresar sus ideas acerca de los fenómenos estudiados. Ante los problemas fundamentales de la Filosofía toda persona asume posturas existenciales que parten de su cotidianidad, el hipertexto facilita la posibilidad de que todos los actores puedan expresar estas posturas, y no sólo el docente.

En un hipertexto pueden estar hospedadas infinidad de opciones útiles para la enseñanza de la Filosofía como por ejemplo: glosario de categorías filosóficas principales, vínculos a bibliotecas virtuales y diccionarios de filosofía, textos de los filósofos, espacios para las discusiones, imágenes, películas reflexivas, juegos y música, lecturas y guías de lecturas varias, orientaciones del docente, programas de los cursos, vínculos con otros cursos de Filosofía de otras universidades y otros materiales relevantes.

Según lo expresado, el hipertexto o hipermedia puede emplearse de acuerdo con la concepción instrumental de la tecnología que se ha mantenido hasta ahora. Estaría mediando la adquisición del conocimiento de estudiantes y profesores a través de nuevos instrumentos conformados por la infinidad de secciones que puede soportar, proporcionando, además una visión de conjunto de la información que contiene. Su instrumentalidad resalta también en cuanto está en servicio de las necesidades particulares de cada uno de los usuarios, pues permite toda clase de combinaciones para la búsqueda de información.

\section{Grupos de discusión electrónicos.}


En la literatura especializada se le conoce con el nombre de: "Computer Conferencing” y es un sistema electrónico asincrónico y textual que clasifica, organiza, almacena y recupera mensajes entre un grupo de aprendices. Burge (1994, p. 21) lo define como "una forma de enviar mensajes de texto sin restricciones de tiempo usando un software especial”, es también, un sistema de comunicación que utiliza redes de computadoras como medio para la discusión y la toma de decisiones colaborativas (Romiszowski, 1997, p. 189), gracias a las facilidades que brinda el software y a su accesible formato, determinados grupos de personas pueden coordinar, organizar y almacenar la información de manera apropiada de acuerdo a sus objetivos comunicacionales. Por ello crea una realidad virtual, un particular sistema social (Harasim et al., 1997, p.19).

Los grupos de discusión electrónicos, en la educación presencial, tienen la ventaja de aumentar el tiempo disponible para las discusiones de clase y la de los grupos de trabajo. Pueden ser usados para establecer relaciones entre estudiantes de distintas sedes de una misma universidad o entre varias universidades, servir de soporte para discusiones privadas de grupos pequeños que elaboran una asignación en conjunto, y atender a las necesidades particulares de un determinado grupo de personas que comparten metas educativas (Harasim et al, idem).

Además, facilita el registro de las participaciones, con lo que da oportunidad para la evaluación del desempeño; permite que las aportaciones sean reflexionadas y bien documentadas; motiva a elaborar contribuciones de mayor calidad, pues existe la tendencia a más ser críticos en el medio escrito que en el oral. Proporciona una mayor retención del aprendizaje, por los procesos cognitivos implicados en la escritura. Ayuda al desarrollo de las habilidades de escritura y de síntesis, da oportunidad a que moderadores y expertos nacionales o internacionales participen en la discusión sin necesidad de estar de forma presencial. Contribuye a crear una visión más global y no sólo regional, pues se puede interactuar con personas de culturas y contextos distintos que requieren de la atención de todos (Escamilla, 1998, p. 132-135).

Wells (1992, p. 21) señala otras aplicaciones de esta tecnología en la educación superior: 
Provee a los estudiantes con oportunidades para la conveniente interacción social y relativa a los cursos con sus compañeros ... capacita grupos de trabajo colaborativo para estudiantes a distancia ... facilita la interacción con el profesor ... disminuye el tiempo de recibir retroalimentación del profesor ... permite a los estudiantes acceder a recursos en línea, por ejemplo, bases de datos, catálogos de bibliotecas, e inscripciones en cursos ... y capacita a los estudiantes para subir y bajar asignaciones y presentar interrogatorios y exámenes.

La mayor ventaja de los grupos de discusión es la oportunidad que ofrece a los estudiantes para trabajar en conjunto y beneficiarse de las contribuciones de sus compañeros. El hecho de que sea comunicación en forma escrita propicia también la ejercitación en el uso adecuado para el contexto comunicativo en marcha.

No obstante, Collis (1997, p. 321) señala algunas debilidades con las que hay que contar en el uso de esta herramienta: el software para grupos de discusión representa un costo adicional al de otras herramientas empleadas como el correo electrónico, y requiere un entrenamiento adicional; a veces, la preselección de categorías en un espacio de discusión no se adapta a los mensajes que se desean publicar; la organización y clasificación de los mensajes no siempre logra orientar a los participantes.

A pesar de esto, los grupos de discusión electrónicos son elementos potenciales de aprendizaje constructivista, como se ha dicho anteriormente, debido a sus capacidades de mediar la conversación y la colaboración. Según Jonnasen et al. (1995, p 16), la construcción del conocimiento se lleva a cabo cuando los estudiantes son capaces de explorar diferentes perspectivas, de tomar posición frente a ellas, de defender con argumentos adecuados tales posiciones y de reestructurar sus propias perspectivas como resultado de la interacción con los diferentes puntos de vista de sus compañeros e instructores.

En ese mismo sentido, los grupos de discusión pueden facilitar el aprendizaje de la Filosofía por las posibilidades que ofrece de explorar perspectivas y de asumir posiciones críticas frente a ellas, por el ejercicio de argumentación que llevan consigo y el manejo adecuado del lenguaje, por la retroalimentación venida de parte del resto de participantes. 
Otras oportunidades que ofrecen los grupos de discusión para el aprendizaje constructivista son: se propicia el surgimiento de múltiples perspectivas sobre un determinado tópico, por lo que todos, incluso el profesor, tienen una gran oportunidad de enriquecerse, debido que a los estudiantes se les ofrecen mayores ocasiones para la participación (Jonassen et al., 1995, p. 16). La interacción no es un simple compartir experiencias sino que busca evaluar y fundamentar con bases sólidas los distintos puntos de vista. Esto, más allá de constituir una mera competencia, se convierte en un trabajo cooperativo en el que cada participante se esfuerza por entender los distintos puntos de vista y se compromete en la construcción común del conocimiento. De ahí que refuerce la tolerancia y el respeto a las ideas de los otros.

El ejercicio de tales actividades fomenta habilidades básicas en el quehacer filosófico como la discusión y argumentación lógica, el respeto a las ideas ajenas, la comprensión de los puntos de vista diversos al propio y el manejo correcto y preciso del lenguaje, escrito, en este caso. Y todo esto sin estar confinados a los límites de tiempo y de espacio, propios de un salón de clases tradicional.

De ahí pues, la identificación de los grupos de discusión con la concepción instrumental o mediadora de la tecnología: en que contribuye con la creación de ambientes para el aprendizaje constructivista, y que en última instancia busca potenciar capacidades propiamente humanas: el conocimiento, la argumentación, el trabajo cooperativo, el pensamiento crítico y el manejo del lenguaje.

\section{Correo electrónico:}

Al igual que los grupos de discusión electrónicos, el correo electrónico o e-mail es una tecnología textual y asincrónica para enviar y recibir mensajes en una red de computadoras, "su uso se limita a la transmisión de información textual, y más recientemente, a la transferencia de documentos o archivos de manera electrónica, por medio de anexos” (Escamilla, 1998, p. 131), en realidad funciona como el correo postal y le sustituye, sólo que con más velocidad y versatilidad.

El correo electrónico es una interesante herramienta de comunicación puesto que está siendo masivamente utilizado alrededor del mundo. Hoy, no sólo los miembros de 
grandes empresas e instituciones tienen acceso a ella sino que, gracias a los proveedores gratuitos de buzones en Internet, la mayoría de usuarios de la gran red han adquirido su cuenta, incluso sin estar limitados a un ordenador particular o redes particulares. Es, probablemente, una de las herramientas de red más ampliamente usadas en todo el mundo (Harasim et al., 1997, p. 204).

En lo que respecta al participante, es una tecnología que permite la comunicación con su instructor sin límite de tiempo ni de espacio, con miras a consultas, aclaraciones, retroalimentaciones, envíos de tareas e incluso para comunicación informal. Permite la comunicación con los otros alumnos, igualmente sin límite de tiempo ni de espacio, por lo tanto, facilita el trabajo colaborativo en la resolución de problemas.

Por ser asincrónico provee de tiempo para la reflexión de lo que se ha de escribir. Exige el ejercicio de habilidades de comunicación en lo que respecta a la elaboración de argumentos bien fundamentados, la ortografía, la tolerancia y el respeto. Proporciona la posibilidad de guardar registro de información relevante recibida así como el procesamiento, edición y reenvío de la misma. Provee la posibilidad de enviar la misma información a varios compañeros de trabajo en una misma operación. Aumenta los niveles de interacción para el estudiante de aprendizaje independiente o a distancia, y le ayuda a disminuir el sentimiento de soledad que a veces experimenta (Haughey \& Anderson, 1998, p. 22).

En otro sentido, Collis (1997, pp. 318-319) enumera algunas ventajas de usar esta herramienta en un ambiente de aprendizaje, desde el punto de vista del docente: el profesor puede registrar los mensajes de los estudiantes captando los dificultades comunes y adelantarse a responder a todos; los mensajes pueden ser respondidos en el mismo texto, lo que hace que el sistema sea manejable; el profesor puede guardar o imprimir copias de los mensajes que envía o recibe, registro que puede serle útil en el futuro; fomenta un contacto amistoso e informal entre estudiantes y profesores, del que a veces se carece en el ambiente presencial; la retroalimentación del profesor puede llegar a convertirse en verdadero contenido de apoyo de la asignatura.

En cuanto al aprendizaje de la Filosofía, el correo electrónico facilita el diálogo informal y hasta extracurricular sobre los distintos problemas que estudia ésta, lo cual 
despierta inevitablemente el interés en los participantes. Muchas veces los tópicos problemáticos de una sesión de clase, suelen fomentar conversaciones y discusiones complementarias que encuentran lugar privilegiado de canalización en el correo electrónico.

Asimismo, el e-mail ha venido a sustituir la carta convencional, medio indispensable usada en épocas pasadas para la comunicación entre pensadores, o entre éstos y sus discípulos. Gracias a estas cartas, se fueron fraguando grandes teorías y grandes obras de la Historia de la Filosofía que han tenido un impacto considerable en la humanidad. Hoy en día el correo electrónico está potenciando esta comunicación, pero de una manera masiva, más versátil y más económica.

Para Burrieza y Rodríguez (2007, p. 2) el correo electrónico y los grupos de discusión (foros de debate) son tecnologías útiles para la enseñanza de la Filosofía, y las han utilizado para llevar a cabo una tutorización virtual. Sin embargo, mientras el correo electrónico facilita una tutoría individualizada, los grupos de discusión permiten el tratamiento de asuntos de manera colectiva, lo que impulsa la discusión entre los miembros y el surgimiento de nuevas cuestiones a tratar.

El uso del correo electrónico en la educación conlleva también a la construcción del conocimiento, como ya se ha acotado, en la medida en que esté orientado a propiciar ambientes de trabajo colaborativo: como herramienta básica de comunicación en la resolución de problemas en equipo, por ejemplo. Cuando el correo electrónico se emplea para ayudar grupos de noticias o de discusión sobre tópicos diversos, puede llegar a transformar esos grupos de personas en verdaderas comunidades de pensadores o comunidades de construcción del conocimiento. Constituye, además una forma de descentralizar el conocimiento, de fomentar la tolerancia y el respeto por las opiniones de los otros (Jonassen et al., 1995, p. 19).

Por lo dicho, el uso del correo electrónico, con estas intenciones educativas, está fundamentado en una concepción instrumental de la tecnología, muy especialmente en la medida en que potencia una capacidad humana: la comunicación. La tecnología serviría, en este caso, de mediación en el diálogo de dos o más personas, en tiempos y lugares diversos. 


\section{CONCLUSIONES}

Luego de la revisión presentada podemos decir que, efectivamente, la tecnología es una mediación que beneficia al hombre en su relación con el mundo, lo cual implica conocerlo y asentarse efectivamente en él. Ese carácter de mediación puede concretarse al usar tecnología para potenciar la enseñanza y aprendizaje de la Filosofía a través de las tecnologías seleccionadas que forman parte de la Red de Internet: a saber, el hipertexto, los grupos de discusión y el correo electrónico.

Considerada así, la tecnología es efectivamente un medio para un fin: la adaptación o asentamiento del ser humano. No debe, por tanto, convertirse en finalidad de por sí. Pues cuando se convierte en fin en sí misma, la producción tecnológica se realiza al margen de sus consecuencias para la vida humana y al margen del asentamiento humano, destruyendo el hábitat adecuado para esa vida.

Desafortunadamente, la raza humana ha emprendido un camino de desarrollo tecnológico que ha pasado por la destrucción sistemática o asistemática de las personas y por un deterioro ambiental tal, que peligra la misma vida del hombre. Todo ello alentado por el afán de poder político, de provecho económico o por el deseo de acabar con el que es diferente. La historia del siglo XX y de lo que va del XXI nos ha dado diversas muestras de este hecho.

La reciente cumbre mundial sobre seguridad nuclear celebrada en abril de 2010 en Washington logró el acuerdo internacional de algunas naciones con miras a evitar el terrorismo nuclear. Sin embargo, este acuerdo representa sólo un mal menor en un mundo dirigido por personas que carecen de madurez suficiente como para manipular la responsabilidad que supone esa caja de Pandora que es la energía nuclear. El acuerdo de la cumbre deja aún tácita la aprobación cómplice de la producción y ensayo nuclear, cuando el mapamundi vive tensiones culturales producto la estrechez de mirada de la mayoría de gobernantes, algunos de los cuales no dudan en aprobar y defender el terrorismo abiertamente.

Por supuesto, no cabe duda, la cumbre ha sido un paso importante. Quizá el siguiente paso sea el Tratado de prohibición completa de los ensayos nucleares. Lo que 
sí está claro es que la humanidad no parece estar todavía preparada para lidiar con las complicaciones que trae consigo la generación de este tipo de energía. La pregunta sobre qué hacer con sus desechos tóxicos sin riesgo de destruir el ambiente todavía sigue sin respuesta.

Es aquí donde cobra auge el principio de mediación de la técnica: lo propio de ésta es facilitarnos una vida conforme a nuestra naturaleza logrando nuestro asentamiento en el mundo. Pero un mundo contaminado y un mundo de amenazas nucleares no conllevan a una vida que merezca la pena ser vivida.

Una actitud interesante frente a situaciones como esta nos la propone el mismo Heidegger (1989) no se trata de desembarazarnos de lo técnico, pues hoy nos es indispensable. La actitud que debe caracterizarnos es la Serenidad: "dejamos entrar a los objetos técnicos a nuestro mundo cotidiano, y al mismo tiempo los mantenemos fuera, o sea, los dejamos descansar en sí mismos como cosas que no son algo absoluto, sino que dependen ellas mismas de algo superior” (p. 27). La actitud de Serenidad es la que sabe decir que "sí" y que "no" al mundo técnico según convenga. Se trata de no dejarnos arrastrar por ellos, que el uso de los objetos técnicos no se convierta en algo inevitable.

Empero, se trata además de comprender que en la técnica hay algo que se nos oculta y a lo que debemos mantenernos abiertos; lo técnico no es simplemente lo instrumental, en él se esconde algo de misterio. Cuando nos mantenemos abiertos al sentido oculto del mundo técnico, estamos abiertos al misterio. Pues "cuando se despierte en nosotros la Serenidad para con las cosas y la apertura al misterio, entonces podremos esperar llegar a un camino que conduzca a un nuevo suelo y fundamento" (Ibidem,pp. 29-30).

Es posible además que esta misma actitud de serenidad nos la dé un incesante hábito de pensar y de reflexionar el mundo tecnológico. Los seres humanos no podemos continuar considerando ingenuamente nuestras acciones técnicas. La Filosofía puede ayudar a fomentar este espíritu inquisidor y cuestionador, tan necesario en nuestros días.

Inclusive, si el aprendizaje de la Filosofía se lleva a cabo desde una plataforma tecnológica como la Internet, y con las tecnologías estudiadas aquí, con mayor énfasis deben propiciarse las ocasiones para pensar nuestra era técnica. Si la tecnología facilita 
esta reflexión, estará cumpliendo su papel de mediadora entre nosotros y la esencia de nuestro quehacer técnico, será un puente que renueve el lazo entre el hombre y el Ser.

\section{REFERENCIAS}

Collis, B. (1997). Tele-learning in a Digital World: The Future of Distance Learning. London: International Thompson Press.

Bravo, M. S. y Montero, A. (2008). La Educación a Distancia en el Escenario Educativo generado por las TIC: Perspectivas y Reflexiones. Educare, Vol 12, № 3, pp. 37 60).

Burge, E. (1994). Learning in Computer Conferenced Contexts: The Learners perspective. Journal of Distance Education, 9, (1), pp. 19-43

Burrieza, A. y Rodríguez, A. (2007) La Enseñanza de la Filosofía en el EEES Mediante el Empleo de Nuevas Tecnologías. Ponencia en línea. II Jornadas de Innovación Educativa y Enseñanza Virtual para la incorporación al EEES en la Universidad de Málaga. Universidad de Málaga. Disponible: www.uma.es/ieducat/II_jornadas/PIE06_024.pdf. Consulta: 2010, Mayo 12.

Escamilla, J. (1998). Selección y Uso de Tecnología Educativa. México: Trillas.

Harasim, L., Hiltz, S., Teles, L. \& Turoff, M. (1997). Learning Networks. A Field Guide to Teaching and Learning Online. Cambridge/Massachusetts/London: The MIT Press.

Haughey, M. y Anderson, T. (1998) Networked Learning. The Pedagogy of de Internet. Montreal/Toronto: Chenelière/McGraw-Hill.

Heidegger, M. (1976). Entrevista del Spiegel, en: Escritos sobre la universidad alemana, Madrid: Tecnos, pp. 49-83.

Heidegger, M. (1989). Serenidad. Barcelona: Serbal.

Heidegger, M. (1994). Conferencias y Artículos. Barcelona: Serbal.

Heidegger, M. (1998) Ser y Tiempo. Santiago de Chile: Editorial Universitaria.

Jonassen, D., Davidson, M., Collins, M., Campbell, J., \& Haag, B. (1995). Constructivism and Computer-Mediated Communication in Distance Education. American Journal of Distance Education, 9(2), 7-26.

Ladrière, J. (1973). Vie Sociale et Destinée. Gembloux (Bélgica): Duculot. 
Laurillard, D. (1997). Rethinking University Teaching. A Framework for the effective use of educational technology. London and New York: Routledge.

Mason, R (1998) Globalising Education. London: Routledge.

Queraltó, R. (1993). Mundo, Tecnología y Razón en el fin de la Modernidad. ¿Hacia el Hombre "More Técnico"? Barcelona: Promociones y Publicaciones Universitarias.

Romiszowski, AJ. (1997) The Use of Telecommunication in Education. En: Dijkstra S., Seel N., Schoot F. \& Tennyson R. (Eds.), Instructional Design: International Pempectives, Volume 2: Solving Instructional Design Problems (pp. 183-220) New Jersey: Lawrence Erlbaum.

Vásquez, A. (2004). El hipertexto y las nuevas retóricas de la postmodernidad. Textualidad, redes y discurso ex-céntrico. Revista Philosophica. N ํ 27, 331 - 350.

Wells, R. (1992). Computer-Mediated Communication for Distance Education: An International Review of Design, Teaching and Institutional Issues. Research Monographs, 6. American Center for the Study of Distance Education, State College, PA; Pennsilvania State University.

Welsh, M. (1998). Orchestrating Multimedia: an Introduction to Planning and Storyboarding Educational Multimedia. Toronto: Irwin Publishing. 